\title{
Pelatihan Permainan Tetris Mathematic Bagi Tentor Genius Course Kebumen
}

\author{
Dyah Anungrat Herzamzam \\ STKIP Kusuma Negara, Jakarat, Indonesia \\ dyah@stkipkusumanegara.ac.id
}

\begin{abstract}
Abstrak
Tujuan kegiatan ini adalah meningkatnya kemampuan tentor atau tenaga pengajar pada lembaga bimbingan belajar genius course dalam bidang pembelajaran dengan menerapkan permainan Tetris Mathematic. Metode yang digunakan adalah pembelajaran orang dewasa (andragogi), dengan perbandingan $20 \%$ teori dan $80 \%$ praktik. Peserta berjumlah 16 orang yang seluruhnya berkualifikasi pendidikan S-1. Hasil yang dicapai: (a) 90\% tentor memiliki kompetensi dalam menerapkan permainan tetris mathematic sesuai dengan pedoman permainan. (b) 100\% tentor mengetahui dan memahami pedoman atau alur permainan. (c) 85\% kemampuan tentor meningkat dalam memvariasikan media pembelajaran. Implikasi kegiatan adalah; (1) Kegiatan Pelatihan penerapan model-model permainan dalam pembelajaran perlu terus ditingkatkan dan dikembangkan, hal ini karena kondisi siswa yang memiliki karakter aktif dalam permaian. (2) Pengembangan proses belajar pada arena belajar non formal perlu diperhatikan, hal ini memiliki standar yang baik.
\end{abstract}

Kata Kunci: Tetris Mathematic, Pelatihan, Permainan

Abstract

The purpose of this activity is to increase the ability of tutors or teaching staff at the genius course tutoring institution in the field of learning by applying the Tetris Mathematical game. The method used is adult learning (andragogy), with a comparison of 20\% theory and 80\% practice. There are 16 participants, all of whom have undergraduate education qualifications. The results achieved: (a) 90\% of the tutors have competence in applying the Tetris Mathematical game according to the game guidelines. (b) 100\% of the tutors know and understand the guidelines or the flow of the game. (c) 85\% of the tutor's ability increases in varying learning media. The implications of the activity are; (1) Training activities for the application of game models in learning need to be continuously improved and developed, this is due to the condition of students who have active characters in games. (2) The development of the learning process in the non-formal learning arena needs to be considered, this has good standards.

Kata Kunci: Tetris Mathematic, Pelatihan, Permainan

\section{PENDAHULUAN}

Pada hakikatnya pendidikan adalah usaha sadar untuk menyiapkan peserta didik melalui kegiatan bimbingan, pengajaran, dan atau latihan bagi peranannya di masa yang akan datang, hal ini menurut Oemar Hamalik (2008). Strategi dalam proses pendidikan dapat dilaksanakan melalui kegiatan pembelajaran dan pengajaran. Artimya adalah bentuk kegiatan yang terjadi interaksi pada proses belajar mengajar baik pengajar dengan siswa. Hal ini dengan tujuan untuk tercapainya hasil yang maksimal dalam proses atau kegiatan belajar mengajar.

Dalam belajar diperlukan dorongan atau motivasi dari guru, orang tua, dan lingkungan siswa. Pada pembelajaran di kelas, motivasi siswa dapat dibentuk dengan bimbingan guru. Guru memberikan kemudahan belajar bagi siswa. Kemudahan dalam belajar matematika salah satunya dapat mengkaitkan pembelajaran matematika dengan permasalahan nyata yang sering dijumpai siswa dalam kehidupan sehari-hari. Oleh karena itu, dorongan dari motivasi guru sangat diperlukan, karena dalam belajar sejatinya merupakan proses menemukan, menurut Yudha, C.B (2018).

Dari observasi yang dilaksanakan di lembaga bimbingan belajar genius course kebumen diperoleh data tentang lembaga kursus yang telah menerapkan model-model pembelajaran yang variatif dan aplikatif. Namun, pada zaman yang semakin berkembang, maka dibutuhkan 
pengembangan peyampaian pembelajaran pada tataran pendidikan kursus. Dalam kursus yang identic dengan nuansa pelayanan untuk siswa agar mampu memiliki tambahan ilmu diluar waktu sekolah. dengan demikian perlunya inovasi penerapan model pembelajaran yang variatif.

Genius course merupakan lembaga bimbingan belajar bidang pendidikan untuk siswa SD sampai dengan SMA sederajad. Mata pelajaran yang disuguhkan adalah bidang matematika, IPA, IPS, Bahasa Indonesia, Bahasa Inggris, tematik, persiapan ujian masuk perguruan tinggi, persiapan kenaikan kelas, persiapan ujian akhir semester, dan persiapan ujian yang setara dengan ujian nasional. Dalam memberikan pelayanan tersebut diharapkan dengan maksimal dapat terlayani sesuai dengan kebutuhan pemilihan kursusnya. Kualifikasi tentor atau pengajarnya adalah berpendidikan minimal S-1. Genius course berdiri sejak tahun 1990 yang waktu itu menerima siswa tingkat PAUD dan SD. Seiring dengan pola manajerial yang adaptif tentang perkembangan zaman, maka sampai dengan saat ini masih melayani bimbingan belajar untuk mendukung pendidikan formal.

Tetris mathematic adalah perpaduan antara permainan puzzle jigsaw dan tetris yang diberikan sisipan soal-soal beserta jawaban dan contohnya pada badan kepingan-kepingan yang didesain menyerupai kepingan-kepingan tetrimino tetris, sehingga cara bermainnya adalah dengan memasangkan kepingan soal, kepingan jawaban dan contoh secara tersusun yang berkaitan dengan soal. Adapun permaian ini merupakan penemuan penelitian pengembangan oleh Alifia, Yudha, Oktaviana (2020). Pola permaiannnya sebagai berikut

1. Untuk memulainya, anda harus menemukan kepingan puzzle tetmath yang memiliki nomor 1 , 2, dan 3 kemudian pasangkan sesuai dengan pola yang benar (puzzle tetmath memiliki pola untuk setiap pasang kepingan yaitu pola S, J, dan C) jika sudah menemukannya lalu posisikan kepingan-kepingan tersebut di pojok kiri atas.

2. S, J, dan C merupakan simbol untuk: S adalah soal, J adalah jawaban, dan C adalah contoh. Setiap kepingan memiliki simbol-simbol ini sesuai dengan isi yang berada di badan kepingan, apakah kepinag tersebut merupakan soal, jawaban, atau contoh, sesuaikan. *lihat gambar pada bag. 2

3. Menyesuaikan kepingan $S$, J, dan $C$ haruslah tepat dan benar yaitu dengan menemukan kepingan bersimbol S (soal) terlebih dahulu kemudian anda mencari pasangannya yaitu kepingan J (jawaban) dan C (contoh) sesuai dengan soal yang dimiliki pada badan kepingan $S$ (soal). Di sini pengetahuan mengenai materi bangun datar (persegi, persegi panjang, dan segitiga) sangat diperlukan agar dapat menyelesaikan puzzle tetmath ini.

4. Jika sudah menemukan S, J, dan C yang tepat dan benar seuai dengan polanya, susun kepingan lain dengan cara yang sama yaitu menemukan kepingan $S$ (soal) terlebih dahulu baru kemudian pasangkan dengan kepingan J (jawaban) dan $\mathrm{C}$ (contoh) yang sesuai dengan kepingan S (soal)nya, lakukan hingga kepingan habis. pola puzzle tetmath dapat dilihat sesekali jika anak mengalami kesulitan memasangkan kepingannya

5. Kepingan tersusun rapi dan pas. Sesuaikan bentuk antar kepingan saat memasangkannya, tidak dengan cara dipaksakan.

Kepingan hitam merupakan tanda bahwa anda telah berhasil memecahkan puzzle tetmath, kepingan tersebut harus dipasangkan setelah semua kepingan habis dipasangkan dan tidak ada yang tersisa.

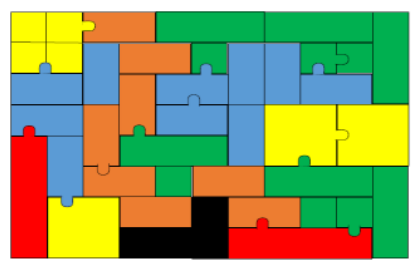

Gambar 1. Pola A Puzzle Tetmath (Tetris Mathematics)

\section{METODE}

\section{Sasaran latih}

Tentor atau pengajar lembaga bimbingan belajar geinus course kebumen yang berjumlah 16 orang. Adapun dari semua tentor ini memiliki kemampuan untuk memberikan pembelajaran pada Mata pelajaran bidang matematika, IPA, IPS, Bahasa Indonesia, Bahasa Inggris, tematik, 
persiapan ujian masuk perguruan tinggi, persiapan kenaikan kelas, persiapan ujian akhir semester, dan persiapan ujian yang setara dengan ujian nasional baik dari siswa SD sampai dengan SMA sederajat.

\section{Materi pelatihan}

Dalam memberikan pelatihan terdiri dari penyampaian teori dan praktik. Perhitungan waktu dengan istital JP yaitu Jam Pertemuan, satu jam pertemuan eqivalen dengan 45 menit. Materi kegiatan dan alokasi waktu yang disediakan disajikan pada tabel 1 berikut:

Tabel 1. Materi pelatihan pelatihan permaian tetris mathematic

\begin{tabular}{|c|c|c|c|c|}
\hline No & Materi & $\begin{array}{c}\text { Praktik/ } \\
\text { Teori }\end{array}$ & $\begin{array}{l}\text { Alokasi } \\
\text { Waktu }\end{array}$ & Narasumber \\
\hline 1 & Ice Breaking & $\begin{array}{c}\text { Teori dan } \\
\text { Praktik }\end{array}$ & $1 \mathrm{Jp}$ & \multirow{4}{*}{$\begin{array}{l}\text { Dyah Anungrat } \\
\text { Herzamam, M.Pd }\end{array}$} \\
\hline 2 & Konsep permaian tetris mathematic & Teori & $1 \mathrm{Jp}$ & \\
\hline 3 & $\begin{array}{l}\text { Penerapan Permaian tetris } \\
\text { mathematic }\end{array}$ & $\begin{array}{l}\text { Teori dan } \\
\text { Praktik }\end{array}$ & $8 \mathrm{Jp}$ & \\
\hline \multicolumn{3}{|c|}{ Jumlah } & $10 \mathrm{Jp}$ & \\
\hline
\end{tabular}

\section{Strategi pembelajaran}

Metode yang digunakan adalah pembelajaran orang dewasa (andragogi), dengan perbandingan $20 \%$ teori dan $80 \%$ praktik. Peserta berjumlah 16 orang yang seluruhnya berkualifikasi pendidikan S-1. Pada pembelajaran orang dewasa, memfokuskan pada peningkatan ketrampilan dan kemampuan untuk memecahkan permasalahan yang mereka alami dalam hidup dan tugas pengabdiannya. Harapannya pada akhir pelatihan atau pembelajaran peserta atau para tentor yang dilatih mampu menerapkannya pada saat berperan sebagai tentor maupun dalam menularkan ilmunya kepada siswa. Pada tahap pembelajaran materi teori, peserta dikumpulkan bersama menggunakan model hybird dan kemudian narasumber menyampaikan materi.

\section{Lokasi penyelenggaraan}

Lokasi penyelenggaraan pelatihan permaian tetris mathematic dilaksanakan dengan metode hybird berbantuan zoom. Para tentor menerima materi pelatihan secara luring di lembaga bimbingan belajar genius course kebumen, yang beralamat di Jalan Veteran no 8 Bumirejo Kebumen Jawa Tengah.

\section{HASIL DAN PEMBAHASAN}

Berdasarkan hasil evaluasi yang dilakukan setelah pelatihan selesai, hasil yang dicapai dari Kegiatan Pelatihan Peningkatan Kompetensi sebagai berikut (a) 90\% tentor memiliki kompetensi dalam menerapkan permainan tetris mathematic sesuai dengan pedoman permainan. (b) $100 \%$ tentor mengetahui dan memahami pedoman atau alur permainan. (c) 85\% kemampuan tentor meningkat dalam memvariasikan media pembelajaran. Hal ini menunjukkan bahwa Pelatihan secara umum merupakan keseluruhan aktivitas yang dirancang untuk meningkatkan potensi atau kinerja peserta dalam melaksanakan pekerjaan mereka, dan pelatihan menjadi bagian dari pengembangan sumber daya manusia. Peraturan Pemerintah RI no.19 tahun 2005 tentang Standar Nasional Pendidikan Pasal 6 Ayat 3 menyatakan bahwa: Satuan pendidikan nonformal dalam bentuk kursus dan pelatihan menggunakan kurikulum berbasis kompetensi yang memuat pendidikan kecakapan hidup dan keterampilan. Dengan demikian peran pelatihan sangat diperlukan dalam menunjang kegiatan pendidikan untuk menciptakan sumber daya manusia yang berkualitas.

Kompetensi pedagogik, profesional dan sosial yang dimiliki seorang pendidik dalam melaksanakan pembelajaran, banyak ditentukan oleh kompetensi kepribadian yang dimilikinya. Kepribadian pendidik dapat mempengaruhi minat dan antusiasme siswa dalam proses pembelajaran. Pribadi pendidik yang santun, peduli terhadap siswa, jujur, ikhlas, menjadi teladan, kekinian, mampu adaptif tentang perubahan zaman, hal ini dapat mepengaruhi tingkat 
keberhasilan dalam pembelajaran yang diampunya. Dengan demikian, guru yang baik adalah mampu memberi contoh, memberikan semangat, dan mendorong untuk kemajuan siswa nya.

\section{KESIMPULAN}

Dari uraian di atas, maka dapat disimpulkan sebagai berikut (a) tentor memiliki kompetensi dalam menerapkan permainan tetris mathematic sesuai dengan pedoman permainan. (b) tentor mengetahui dan memahami pedoman atau alur permainan. (c) kemampuan tentor meningkat dalam memvariasikan media pembelajaran. Implikasi kegiatan adalah; (1) Kegiatan Pelatihan penerapan model-model permainan dalam pembelajaran perlu terus ditingkatkan dan dikembangkan, hal ini karena kondisi siswa yang memiliki karakter aktif dalam permaian. (2) Pengembangan proses belajar pada arena belajar non formal perlu diperhatikan, hal ini memiliki standar yang baik

\section{REFERENSI}

Aifah, Ratu Risky., Yudha, Chrisnaji Banindra., Oktaviana, Eva. 2020. Pengembangan Media Permainan Puzzle Tetris Mathematics pada Materi Bangun Datar. Prosiding Seminar Nasional Pendidikan STKIP Kusuma Negara II. ISSN 2716-0157.

Oemar Hamalik, Kurikulum dan Pembelajaran (Jakarta: PT Bumi Aksara, 2008), Peraturan Pemerintah RI no.19 tahun 2005 tentang Standar Nasional Pendidikan. Jakarta: Depdikbud

Sunarsi, D. (2018). Analisis Motivasi Kerja Tenaga Pendidik Sukarela Pada Pusat Kegiatan Belajar Masyarakat (PKBM) Bimasda Kota Tangerang Selatan. Kreatif: Jurnal Ilmiah Prodi Manajemen Universitas Pamulang, 6(2), 53-65.

Yudha, C.B. 2018. Peningkatan Motivasi Belajar Mahasiswa Pada Mata Kuliah Konsep Dasar Matematika Melalui Pendekatan Contextual Teaching And Learning. JPD: Jurnal Pendidikan Dasar Vol 9 Nomor 1 p.12-27. 